\title{
Does 'proximal control' need a new definition or a paradigm shift in exercise prescription? A clinical commentary
}

\author{
Steven L Dischiavi, ${ }^{1,2}$ Alexis A Wright, ${ }^{1}$ Eric J Hegedus, ${ }^{1}$ Kevin R Ford, \\ Chris Bleakley ${ }^{1,2}$
}

\section{WHAT CONSTITUTES PROXIMAL CONTROL?}

There is level 1 evidence that 'proximal control' exercises are effective in the management of common musculoskeletal injuries of the lower extremity. ${ }^{1}{ }^{2}$ However, there is little agreement on what 'proximal control' entails. A meta-analysis by Sugimoto et $a l^{2}$ examined neuromuscular training for ACL injury prevention and found that exercises incorporating a 'proximal control' component (OR 0.33, 95\% CI 0.23 to 0.47 ) were comparable to strength-based exercise or 'multiple exercise' interventions. Sugimoto $e t l^{2}$ chose a global definition of proximal control (any exercise involving segments proximal to the knee joint) which included full-body dynamic warm-up programmes with plyometrics, jumps/hops, bounding, and various running and agility movements. One might argue that while these full-body interventions represent an integrated holistic approach, calling them 'proximal control' is inaccurate, as they fail to incorporate hip-specific exercises as the next 'proximal' link in the kinetic chain.

In comparison, a review by Lack et $a l^{1}$ reported on the benefits of proximal control interventions for patellofemoral pain syndrome defining 'proximal control' as 'exercises directed at the hip or lumbopelvic musculature or both.' Consequently, Lack et al's review $^{1}$ was limited to more traditional static, hip-focused movements, such as side-lying or standing hip abduction and seated external rotation strengthening exercises. These hip-focused exercises are certainly 'proximal' in relation to the

'Department of Physical Therapy, High Point University, High Point, North Carolina, USA

${ }^{2}$ Sport and Exercise Sciences Research Institute, School of Sport, Ulster University, Newtownabbey, UK

Correspondence to Dr Steven L Dischiavi, Department of Physical Therapy, High Point University, 1 University Parkway, High Point, NC 27268, USA; sdischia@highpoint.edu knee, but one might question whether such a reductionist approach translates into upright, complex, sport-related movements.

\section{PROXIMAL CONTROL AS IT RELATES TO THE KINETIC CHAIN}

The aforementioned research ${ }^{12}$ reflects a pragmatic approach to proximal control exercise prescription. Although there is evidence of clinical effectiveness, this evidence is not consistent across all outcome measures. For example, when slow, static, single-plane, hip-focused proximal control exercises were applied to runners, they failed to alter proximal mechanics during running, ${ }^{3}$ suggesting hip-focused proximal control exercises do not translate to high-speed, complex sporting activities. Similarly, 'proximal control' programmes in the ACL literature, that lack a hip-focused approach, have centred on generalised full-body dynamic warm-up type activities, ${ }^{2}$ but despite the extensive research and development in this field, few sports are reporting subsequent reductions in ACL injury incidence. ${ }^{4}$

We present a new concept that embraces a complex intervention paradigm, 5 where exercises are designed around the arthrokinematics, biomechanics and global physical demands of the entire kinetic chain. Our blended approach incorporates components of both hip-focused exercise and full-body dynamic movements to more accurately reflect contemporary clinical practice. We would postulate that this amalgamated approach, where hip-focused exercises are delivered at higher speeds across multiple planes, will incorporate more of the specific elements needed for complex sporting movements.

The central tenet of this approach is the integration of the trunk as the primary lever for resistance rather than the femur. ${ }^{1}$ Utilising the trunk as the moving lever over a fixed femur may provide more innovative ways to create strength and neuromotor changes at the hip allowing for more global and complex exercises to be termed 'proximal control'. Incorporating resistance at the proximal trunk offers several unique variations when compared with conventional hip interventions, including introducing rotational forces about the vertical $\mathrm{z}$-axis. Resistance about the z-axis replicates the spiralling effect of the lower extremity when managing ground reaction forces (GRF). Also, leaving the lower extremity unobstructed from points of resistance allows for the integration of triplanar eccentric-based movements at increasing speeds attempting to attenuate the GRFs needed during complex movements such as running.

\section{IMPLICATIONS FOR CLINICAL PRACTICE}

It would appear that existing 'proximal control' programmes sit across two extremes where they are either limited to simplistic, single-plane, hip-focused exercises, or are generalised dynamic warm-up activities, which lack the integration of a hip-focused approach. The challenge for clinicians is to work within a paradigm that allows exercises to remain 'proximal control' and hip focused but gives the clinician manoeuvrability to apply these hip-focused exercises with increasing complexity. Complexity includes incorporating the various elements needed to perform sporting activities such as speed, endurance, ballistic movements, motor control and triplanar movements that manage eccentric loads at varying joint angles. Therefore, as complexity of the exercises increases so do the number of components of sport-specific movements. A new paradigm would provide clinicians with a conceptual framework for progressing proximal control exercises while maintaining a hip-focused approach as more complex exercises are designed (figure 1).

The salient features of the work presented here are the blending of the reductionist and holistic philosophies by integrating the hip into a comprehensive spectrum of proximal control exercises. Future interventions in this field must evolve, appreciating the complexities of human movement and to better reflect current progressive clinical practice patterns. The clinical benefit of adopting a new paradigm of 'proximal control' exercise is being able to maintain the emphasis on the hip and its proximal influence over the lower extremity while 


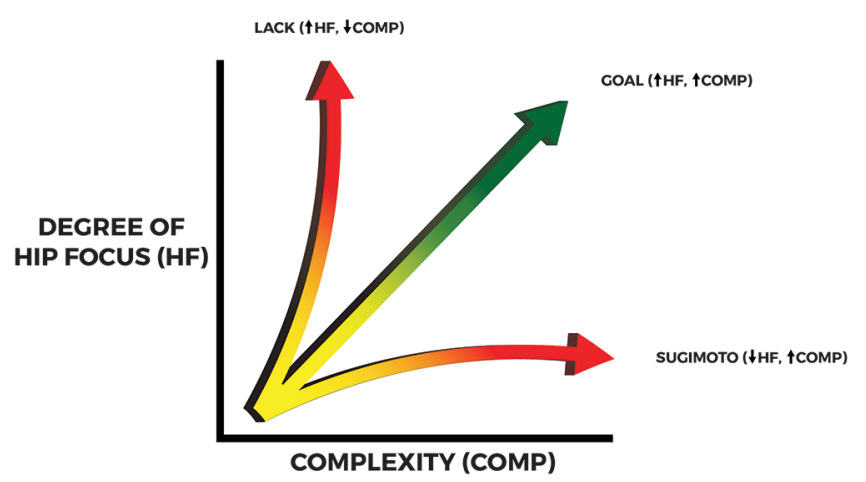

Figure 1 Clinical progression of hip-focused proximal control exercise. The goal of proximal control exercise should be to have a high degree of hip focus while the complexity of the exercise is increasing. A blended paradigm from the two mentioned systematic reviews would allow the clinician to maintain a high degree of hip focus while progressively increasing the complexity of the exercises with the end result being a highly hip-focused intervention with the complexity that reflects the specific movement needed by the athlete.

increasing the complexity of the intervention through the progressive addition of necessary elements needed to accommodate sport-specific demands.

\section{Twitter @finishfirst_pt}

Competing interests None declared.

Provenance and peer review Not commissioned; externally peer reviewed.

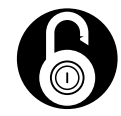

\section{OPEN ACCESS}

Open access This is an open access article distributed in accordance with the Creative Commons Attribution Non Commercial (CC BY-NC 4.0) license, which permits others to distribute, remix, adapt, build upon this work non-commercially, and license their derivative works on different terms, provided the original work is properly cited and the use is non-commercial. See: http:// creativecommons.org/licenses/by-nc/4.0/

(C) Article author(s) (or their employer(s) unless otherwise stated in the text of the article) 2019. All rights reserved. No commercial use is permitted unless otherwise expressly granted.

D) Check for updates
To cite Dischiavi SL, Wright AA, Hegedus EJ, et al. Br J Sports Med 2019;53:141-142.

Accepted 4 October 2017

Published Online First 1 December 2017

Br J Sports Med 2019:53:141-142.

doi:10.1136/bjsports-2017-097602

\section{REFERENCES}

1 Lack S, Barton C, Sohan 0, et al. Proximal muscle rehabilitation is effective for patellofemoral pain: a systematic review with meta-analysis. Br I Sports Med 2015;49:1365-76.

2 Sugimoto D, Myer GD, Foss KD, et al. Specific exercise effects of preventive neuromuscular training intervention on anterior cruciate ligament injury risk reduction in young females: metaanalysis and subgroup analysis. $\mathrm{Br} /$ Sports $\mathrm{Med}$ 2015;49:282-9.

3 Willy RW, Davis IS. The effect of a hip-strengthening program on mechanics during running and during a single-leg squat. J Orthop Sports Phys Ther 2011;41:625-32.

4 Agel J, Rockwood T, Klossner D. Collegiate ACL injury rates across 15 sports: national collegiate athletic association injury surveillance system data update (2004-2005 Through 2012-2013). Clin J Sport Med 2016;26:518-23.

5 Bekker S, Clark AM. Bringing complexity to sports injury prevention research: from simplification to explanation. Br J Sports Med 2016;50:1489-90. 